Lymphoedema is defined as swelling, particularly of the skin and subcutaneous tissues, due to increased lymph content resulting from an impaired lymphatic drainage. The term originated in the United States appearing as early as 1895 (Dennis). As late as 1914, however, Choyce's text-book does not use it, although giving an excellent account of the condition under the heading of lymphatic obstruction. In recent years it has been used loosely to cover chronic oedema of any type, for instance, that caused by chronic venous incompetence in the leg. If such oedema is included, it is difficult to exclude other chronic oedemas, either local or constitutional. The term then loses any value and were better discarded.

In clinical practice many cases are seen in which the aetiology is entirely obscure. The term ' lymphoedema' should be reserved for such of them as are believed to be of lymphatic origin.

\section{Historical}

Nonne (1891), Milroy (1892) and Meige (1898) independently described a congenital, hereditary form of swelling of the lower limbs, of unknown aetiology. Milroy (of Omaha) by whose name the condition is commonly known, described the case of an otherwise robust clergyman, 31 years old, who came to be examined for life insurance. His only abnormality was the presence of bilateral oedema of the legs below the knees, which had been present since birth. On further inquiry it was established that of 97 persons in 6 generations in the patient's family, no fewer than 22 had suffered since birth from swelling of one or both legs. The cardinal points of the condition laid down by Milroy were :-

(r) The swelling is present at birth.

(2) Other members of the family are involved.

(3) The legs only-either one or both-are involved.

(4) The condition is persistent ; only in one exceptional case did the swelling disappear.
(5) It is never attended by constitutionalo symptoms.

Milroy's disease is, therefore, a congenital, i hereditary, otherwise symptomless oedema of ${ }_{\omega}^{\infty}$ one or both legs. Osler's comment to Milroy was N that it might be a form of angio-neurotic oedema.

Allen (1934) of the Mayo Clinic introduced the or term lymphoedema praecox to denote cases which은 come on between the ages of 10 and 24 years, particularly in women ( 87 per cent.).

Sabouraud (1892) and Unna (1896) drewo attention to the importance of streptococcal $\stackrel{\text { क }}{\rightarrow}$ infection in progressive lymphoedema, whilgt $\overrightarrow{0}$ Homans (1936) recovered the responsible stre - N tococcus from experimental dogs developing the condition.

\section{Types and Aetiology}

Lymphoedema may be :

(I) Primary or idiopathic :

(a) Congenital, either non-hereditaryō or hereditary (Milroy).

(b) Praecox, developing in early life

(2) Secondary to

(a) Trauma, either accidental, operative or radiotherapeutic.

(b) Infection ; particularly filarial or streptococcal.

(c) Neoplastic infiltration.

The aetiology of the primary or idiopathic types ${ }^{\circ}$ is obscure. Absence or failure of valves in theo lymphatic system has been postulated as a cause.

Secondary types arise from a variety of causes. N After injury to the face, lips and eyelids, so-calledro 'post-traumatic oedema' is not uncommon. N Oedema persisting after a simple fracture is ${ }^{\omega}$ similar in origin. Lymphoedema is seen in its simplest form following removal of regionale lymphatics as after block dissection of the glandse of the groin. Pitting oedema of the leg results, which is controlled by rest and elevation. In the absence of recurrence of the malignancy, with due care and support the oedema improves and is 
likely to disappear. After radiotherapy for malignant disease, lymphoedema is not uncommon. In its production both disease and treatment may be factors ; it is impossible to apportion responsibility between them ; the combination must be blamed.

Lymphoedema may arise from purely inflammatory causes, particularly on the face, about the eye, as in recurrent erysipeloid infections. These may be accompanied by malaise, fever and chills, with the rapid appearance of swelling at one particular spot. This swelling comes to persist between attacks and progresses with characteristic changes in the skin. A similar condition occurs in the leg, the inflammation starting often between the toes where fungus infection may play a part, and may result in progressive, disabling swelling of the whole lower limb (Homans 1936, Ochsner 1940). Weinstein (1950) gives a full account of such a case with oedema up to and including the vulva, treated and followed over 20 years.

Filarial lymphoedema or elephantiasis is due to blocking of lymphatics by the filarial parasites and by the inflammation and fibrosis they cause. It leads to enormous and disabling enlargement of the lower limbs and external genitalia. Surgical measures may be called for and consist of removal of the offending areas.

Lymphoedema can be caused by cancerous infiltration of the lymphatics of the axilla or groin, as in cases of carcinoma of the breast or of the external genitalia, or of malignant melanoma of the as in cases of carcinoma of the breast, or of the external genitalia or of malignant melanoma of the skin. Compression or involvement of veins may also play a part in its development, whilst subsequent surgical intervention, radiotherapy and infection all tend to complicate the issue. The swollen arm seen after radical amputation of the breast may result from any or all of these factors. In general, those cases which occur early (within 2. months of operation) are due to infection and are likely to be of good prognosis ; those occurring later are more likely to be due to recurrence of the growth and are of more serious import.

Lymphangiosarcoma (Stewart and Treves 1948, Ferraro 1950, Jessner et al. 1952), may develop in such an arm after a lapse of years. It presents with multiple, bluish, raised spots on the skin of the arm and has so far been invariably fatal. Its relation to the original carcinoma is not understood.

In gravitational or varicose conditions of the leg, particularly after thrombosis of the deep veins, oedema arises primarily from venous incompetence. With the onset of eczema or ulceration, bacterial inflammation is added. Recurring attacks of cellulitis of the surrounding tissues cause increasing fibrosis, lymphatic obstruction and swelling. Lymphoedema is therefore superimposed on the original varicose condition but $\frac{3}{8}$ only secondarily, as the result of infection.

\section{Pathology}

Macroscopically, the skin and subcutaneous $\stackrel{\text { ? }}{\square}$ tissues are enormously thickened, the skin being $\underline{ }$ coarse and leathery. On incision the subcu- $\frac{\overline{\bar{\sigma}}}{\frac{\overline{2}}{6}}$ taneous tissues are superficially translucent and $\underset{8}{\circ}$ weep clear fluid; more deeply the fluid is cloudy with increasing fibrosis of the tissues which are क hardly distinguishable from the deep fascia. This $\vec{\circ}$ is thickened, but its deep surface and the under- $\vec{\overrightarrow{ }}$ lying muscle appear normal.

Microscopically, the characteristic features are $\bar{Q}$ those of replacement of the normal fat by dilated 3 . lymph spaces, with all stages of fibroplastic proliferation particularly involving the deeper layers $\stackrel{\infty}{\omega}$ near the deep fascia. The underlying muscle $N$ shows no abnormality.

\section{Clinical Features}

Mowlem (1948) describes three clinical phases in the progress of the condition:

Phase I. The swelling is peripheral, soft and disappears in 48 hours with elevation and rest. $\stackrel{\oplus}{+}$

Phase II. The oedema is marked, still pif $\vec{\varphi}$ on pressure but is not entirely removed bo rest and elevation. The skin becomes tense shiny, loses its hair and weeps excessively aft injury. Histologically this is the stage of developing fibrosis.

Phase III. The swelling is woody, does not $\frac{\varrho}{\varnothing}$ pit on pressure and is little affected by rest and $\cong$ elevation. The lymphatics are surrounded by fibrosis, the whole being a sclerotic mass. This is the stage of frank elephantiasis, the term conveying both the size, thickening and texture of the skin.

In those cases which are the result of infection, attacks of inflammation are accompanied by vary- 3 . ing general signs; these may be of all degrees from slight to disabling with chills and high fever. Locally the skin is painful, red, swollen o and tender; red lines may be evident running up towards the regional lymph glands. The pressure $\frac{T}{0}$ of a bandage may be painful and support may therefore be omitted by the patient.

\section{Treatment}

In the primary group of unknown aetiology, 0 whether simple, hereditary or ' praecox,' treatment is symptomatic. In milder cases, swelling $\stackrel{0}{\odot}$ can be improved by physiotherapy and by firm $\stackrel{\oplus}{\oplus}$ elastic bandaging. If the condition progresses, as is likely, surgery is the only treatment of avail. Wide excisions of the subcutaneous tissues and $\frac{\nabla}{\circ}$ deep fascia, implanting the skin on the muscles, $\frac{O}{\circ}$ 
restores shape to the leg and has caused vast relief. Operations of this type, developed particularly by Homans (1936), Ochsner (1940) and Macey (1948), have replaced the original Kondoléon (1912) procedure in which strips of the deep fascia were excised with the object of establishing communication between the superficial and deep lymphatic systems. As even the presence of lymphatics in muscles has been questioned, it is not surprising that the method proved unsatisfactory. The object of the more radical recent operations is to remove the whole area of subcutaneous tissue capable of swelling, leaving only skin and muscle.

In the secondary groups treatment is directed first to the cause. In traumatic conditions physiotherapy may be curative. In the inflammatory types, in the acute stage rest is combined with full systemic chemotherapy. When the acute stage has subsided everything possible is done to eradicate infection from the skin by cleanliness, physiotherapy and by treatment of fungus infections if present. If, in spite of repeated courses of chemotherapy and all possible care, infection recurs and damage is progressive, the area from which the infection starts can be excised and, if necessary, grafted. This may be curative but must obviously be undertaken before the condition has progressed too far.

In the lymphoedema secondary to varicose conditions, treatment is directed firstly to the infection. Streptomycin has proved to be the most useful antibiotic in these conditions. Reserved at first for systemic administration, it has now been shown to be effective locally and can be used successfully in the outpatient department (Monro, I95I). Carefully applied support to the limb however is the key to success. In the early stages, occlusive dressings by Unna's method, with bandages of the Viscopaste type or with adhesive elastic bandages (Elastoplast type) are valuable. To avoid reactions in sensitive patients much work has been done in eliminating possible sensitizing agents from adhesive bandages and porous and ڤ synthetic types of Elastoplast are now under trial. 3 The most effective type of support however is $\cong$ unquestionably given by an elastic bandage, $\stackrel{\hookrightarrow}{.}$ applied by the patient himself before getting out $\underset{\vec{D}}{\vec{D}}$ of bed in the morning and reapplied after resting the leg up at mid-day. "One-way-stretch' bandages are ideal for this purpose and have $\frac{\bar{c}}{\bar{c}}$. proved themselves invaluable. Carefully shaped $\underset{\mathbb{D}}{\widetilde{D}}$ elastic stockings are helpful for cases of lesser 2 degree, especially for women who are able to plan os their own day.

Surgical treatment for the underlying venous incompetence is then instituted.

In malignant conditions, if the swelling is due to cancerous involvement, treatment is palliative $\frac{0}{3}$ by radiotherapy, rest, elevation, and firm elastic bandaging. If due to infection or to radio- $\infty$ therapy without evidence of recurrent growth, further measures have to be considered. Grafting of healthy skin flaps across to the limb combined जा with Kondoléon type operations have been helpful, 은 whilst in cases with severe pain even amputation has been necessary.

\section{BIBLIOGRAPHY}

ALLEN, E. V. (1934), Proc. Mayo Clin., 9, i 2. DENNIS,F. S., and BILLINGS, J. S. (1895), 'System of Surger

Vol. II, p. 47I. Philadelphia : Lea Bros. and Co. FERRARO, L. R. (1950), Cancer, 3, 51 I. GHORMLEY and OVERTON (1935), Surg. Gynec. Obstet., 6r, $8 \overrightarrow{3}$ HOMANS, J. (1936), Nero Eng. F. Med., 215, 1099. JESSNER, M., et al. (1952), Arch. Derm. Syph., 65, 123. KONDOLEON (I912), Munch. med. Wschr., 59, 2726. MACEY, H. B. (1948), f. Bone ft. Surg., 30A, 339. MEIGE, H. (1898), Pressé med., 6, 34I.

MILROY, W. F. (1892), N.Y. med. $\mathscr{f} ., 56,505$. MONRO, A. K. (1951), Brit. Med. F., 2, 97 r. MOWLEM (1948), Brit. F. plast. Surg., I, 48. NONNE, M. (1891), Virchow's Arch., 125, 189. OCHSNER, A. (1940), Surgery, 8, 383.

SABOURAND, R. (1892), Ann. Derm. Syph., 3, 592. SISTRUNK, W. E. (1927), Ann. Surg., 85, 190.

STEWART, F. W., and TREVES, N. (1948), Cancer, $1,64$. UNNA, P. G. (1896), 'The Histopathology of the Diseases of the Skin,' pp. 492-493. Edinburgh : William F. Clay.

WEINSTEIN, M., and ROBERTS, M. (1950), Amer. F. Surg 79, 327 .

\title{
The Book on
}

\section{ChEMOTHERAPEUTIC AND ANTIBIOTIC DRUGS}

The Postgraduate Medical Journal's series of articles on the present status of the Chemotherapeutic and Antibiotic Drugs commenced in August 1951, and finished in the March 1952 issue

Published by

\author{
THE FELLOWSHIP OF POSTGRADUATE MEDICINE \\ 60 PORTLAND PLACE, LONDON, W.I \\ PRICE 5s. plus 3d. postage
}

